\title{
Bem Viver: herança-sintonia-compromisso com a Casa Comum
}

\author{
Rosemary Fernandes da Costa ${ }^{1}$
}

Que tempos estamos vivendo? Tempos nos quais nos defrontamos com processos de desenvolvimento tecnológico e industrial de tal sofisticação e com abismos nos processos de relacionamentos e harmonia entre seres humanos e natureza? Será que ao cuidarmos do desenvolvimento nos esquecemos de cuidar do fundamental para todos: a vida? Todos os dias temos experimentado calamidades ambientais e também a ausência de uma mínima visão de fraternidade, justiça e equidade. Perplexos, nos damos conta de que algo precisa ser revisto, contudo, a complexidade sistêmica, político e econômica, tem feito com que muitas pessoas silenciem, paralisem, não por ausência de um discernimento ético, mas devido à própria impotência diante da grandiosidade da crise na qual estamos inseridos.

Em sintonia com o sofrimento da humanidade e do planeta, e respondendo aos apelos que chegam de sua própria vocação, o Papa Francisco convoca que cuidemos juntos da Casa Comum². E alerta para a necessidade de mudarmos a forma como fazemos a economia - o cuidado da casa ${ }^{3}$ - e, com isso, mudarmos a maneira como nos organizamos em sociedade. É preciso que todos se unam neste desafio, em uma solidariedade universal.

Lanço um convite urgente a renovar o diálogo sobre a maneira como estamos a construir o futuro do planeta. Precisamos de um debate que nos una a todos, porque o desafio ambiental, que vivemos, e as suas raízes humanas dizem respeito e têm impacto sobre todos nós. O movimento ecológico mundial já percorreu um longo e rico caminho, tendo gerado numerosas agregações de cidadãos que ajudaram na conscientização. Infelizmente, muitos esforços na busca de soluções concretas para a crise ambiental acabam, com frequência, frustrados não só pela recusa dos

\footnotetext{
${ }^{1}$ Rosemary Fernandes da Costa é doutora em Teologia Sistemático-Pastoral pela PUC-Rio, professora da Cultura Religiosa na PUC-Rio. Organizadora do livro $A$ Mística do Bem Viver (2019), editado pela Senso, BH; e autora dos livros Mistagogia hoje (2014) e A Mistagogia em Cirilo de Jerusalém (2015), pela Paulus, SP.

2 PAPA FRANCISCO. Carta Encíclica Laudato Si. Sobre o cuidado da casa comum. Vaticano: Libreria Editrice Vaticana, 2015. Disponível em: http://w2.vatican.va, acesso em fevereiro, 2020

${ }^{3}$ A palavra economia tem sua origem no latim OECONOMIA, que por sua vez é derivada do grego OIKONOMIA, ambas remetem ao cuidado da casa - oikos (casa) + nomein (gerenciar).
} 
poderosos, mas também pelo desinteresse dos outros. As atitudes que dificultam os caminhos de solução, mesmo entre os crentes, vão da negação do problema à indiferença, à resignação acomodada ou à confiança cega nas soluções técnicas. Precisamos de nova solidariedade universal. (LS 14)

Neste pequeno artigo refletiremos sobre o tema do Bem Viver, seu significado, sua inspiração para nossa sociedade, suas possibilidades e seus desafios. Para darmos alguns passos nessa direção, estaremos atentos à herança que nos chega dos povos originários da América Latina em sua cosmovisão e relação ética com a Terra. Nessa busca de sintonia, traremos alguns pensadores contemporâneos que tem se dedicado a esta reflexão e confirmaremos nossos passos em unidade com as preocupações do Papa Francisco, expressas na Carta Encíclica Laudato Si e no processo de discernimento que culminou com o Sínodo para a Amazônia ${ }^{4}$, um marco histórico e sacramental não apenas para caminhada missionária e ética da Igreja Católica, mas para o mundo. São passos de um discipulado radicado no mestre Jesus Cristo em seu processo pascal e, para o qual, o Papa Francisco nos impulsiona profeticamente para uma Igreja em saída. ${ }^{5}$

No paradigma atual chegamos aos limites de alguns conceitos que nos conduziram nas últimas décadas como, por exemplo, a ideia de progresso, de desenvolvimento, de colonialismo. Aparentemente estes conceitos estavam consolidados na América Latina. Contudo, mesmo os governos progressistas, já percebem os limites políticos, ideológicos e econômicos destes referenciais. No momento atual, estamos vivendo uma crise tão potente que não é mais possível frear a devastação e exploração da Terra e nem o grito das populações empobrecidas por esta ideologia.

Portanto, a convocação que brota do chão da Terra e de todos os povos sensíveis ao sofrimento humano e da terra, é

\footnotetext{
${ }^{4}$ No mês de outubro de 2019 , depois de um longo processo de assembleias locais por toda a América Latina especialmente na região Amazônica, ocorreu a Assembleia Especial do Sínodo dos Bispos para a Região Pan-Amazônica: Amazônia: Novos Caminhos para a Igreja e para uma Ecologia Integral. De acordo com o Papa Francisco, "o objetivo principal desta convocação é identificar novos caminhos para a evangelização daquela porção do Povo de Deus, especialmente dos indígenas, frequentemente esquecidos e sem perspectivas de um futuro sereno, também por causa da crise da Floresta Amazônica, pulmão de capital importância para nosso planeta."

5 "Igreja em saída" é um termo cunhado pelo papa Francisco na exortação apostólica Evangelii Gaudium. Cf. FRANCISCO. Exortação Apostólica Evangelii Gaudium sobre o anúncio do Evangelho no mundo atual. São Paulo: Paulinas, 2013
} 
buscarmos uma alternativa a esses referenciais que se tornaram destrutivos e, assim, sem condições de com eles prosseguir. É uma busca que vai muito além de uma luta política ou por um modelo socioeconômico. É um retorno ao que é mais precioso, fundante, originário e portador de vida para todos: se trata de percebermos que tudo está inter-relacionado - o humano, o cósmico, o divino - e que o ser humano não é o centro, e sim parte do cosmos.

É o que as culturas originárias chamam de Bem Viver. É uma visão de mundo, um princípio ativo que dinamiza cada escolha, cada passo, cada gesto. Nele se fundam práticas como a reciprocidade, a solidariedade, a não acumulação, a convivência fraterna e zelosa com tudo e com todos. Ao reconhecermos essa visão como um fundamento, um princípio ativo, todo o resto necessita se reorganizar em nosso entorno. Se reconhecemos uns aos outros como irmãos, como devemos olhar, perceber, cuidar, de cada pessoa que habita esse chão comum? Se reconhecemos que tudo está interligado, como nos alimentamos? O que consumimos? Como descartamos o que não consumimos? O que orienta nossas escolhas cotidianas? São questões que brotam de dentro para fora, elas convocam, são como vozes interiores que dialogam com nossa consciência, com nossa sensibilidade, com as necessidades que percebemos nas pessoas e no ambiente. É um novo jeito de se movimentar no dia a dia, que nos reconduz também a uma nova espiritualidade.

O Bem Viver resgata em cada um de nós uma espiritualidade profunda, integral. Nos oferece - como um presente desejado e, ao mesmo tempo, já conhecido -, o sentido de pertença a Terra, à natureza, ao universo, à vida, ao Espírito Criador. É uma experiência eco-espiritual que nos ajuda a deixar de considerar o ser humano como centro e amplifica nosso olhar, englobando todo o cosmos e nos entendendo como parte do mesmo.

Os povos indígenas chamaram toda essa inspiração de Sumak Kawsay, de Buen Vivir, ou de Teko Porã. Para a bióloga equatoriana Esperanza Martínez, "o Bem Viver é mais do que viver melhor, ou viver bem: o bem viver é viver em plenitude". 6 É importante demarcarmos que esta concepção vem dos povos

${ }^{6}$ SBARDELOTTO, M. Nem melhor, nem bem: viver em plenitude. Entrevista a Esperanza Martinez. In: Sumak Kawsay, Suma Qamana, Teko Pora. O Bem-Viver. IHU online. São Leopoldo: Unisinos, edição 340: agosto de 2010. Disponível em http://www.ihuonline.unisinos.br/artigo/3448-esperanza-martinez, acesso em fevereiro de 2020. 
indígenas, de uma cosmovisão ancestral, uma sabedoria milenar, que aponta na direção de que os vínculos entre a terra e a natureza não podem ser quebrados.

O termo usado não é alli kawsay (bem viver), mas sim sumak kawsay (viver em plenitude). A meta é a plenitude. Pensemos nesta meta, o que ela supõe para a comunidade humana, ambiental e cósmica?

Será esta a direção que temos tomado com os referenciais do desenvolvimento, do colonialismo, da ideia de progresso? E mais. Será que os povos indígenas estavam enganados ou atrasados, como muitos de nós aprendemos? O que seria, pensando em tudo isso, o conceito de civilização?

Convencidos de que os referenciais da sociedade capitalista seriam os melhores para todos, nossa chamada civilização moderna trata a natureza como objeto, e com isso, se vê no direito de explorar, destruir, em benefício exclusivo. Os objetivos são o desenvolvimento tecnológico, industrial, urbano, a eficácia, o progresso, lucros rápidos. E ainda nos equivocamos pensando que a tecnologia seria capaz de reparar qualquer dano. $\mathrm{Na}$ verdade, os esforços tecnológicos e industriais também se direcionam neste sentido, mas não como preocupações emergenciais.

$\mathrm{Na}$ Exortação Apostólica Querida Amazônia, o Papa Francisco nos impulsiona a entrarmos em comunhão com a dor que brota da terra violentada pelos interesses desenvolvimentistas. ${ }^{7}$

Os interesses colonizadores que, legal e ilegalmente, fizeram e fazem aumentar o corte de madeira e a indústria minerária e que foram expulsando e encurralando os povos indígenas, ribeirinhos e afrodescendentes, provocam um clamor que brada ao céu:

"São muitas as árvores

onde morou a tortura

e vastas as florestas compradas entre mil mortes".

"Os madeireiros têm parlamentares

e nossa Amazônia não tem quem a defenda (...)

Mandam em exílio os papagaios e os macacos (...)

Já não será igual a colheita da castanha”.(QA 9)

7 PAPA FRANCISCO. Exortação Apostólica Pós-Sinodal Querida Amazonia. Vaticano: Libreria Editrice Vaticana, 2020. Disponível em http://www.vatican.va/content/francesco/pt/apost_exhortations/documents/papafrancesco_esortazione-ap_20200202_querida-amazonia.html. Acesso em fevereiro de 2020 
Para a cosmovisão indígena a natureza é sujeito, e não objeto. Ela está viva e todos pertencemos a ela, somos filhos da Mãe Terra (a Pachamama). Desta atitude de reverência e contemplação, surgem atitudes que respeitam os ciclos vitais de cada espécie, e a partir desta sabedoria, compartilham respeitosamente. Sim, para a cosmovisão sumak kawsay, a terra é rica e somos todos participantes dessa riqueza, que é a biodiversidade e as infinitas formas e interagir com ela.

Em seu livro sobre o Bem Viver, Alberto Acosta $^{8}$ afirma:

"Com sua proposta de harmonia com a Natureza, reciprocidade, relacionalidade, complementariedade entre indivíduos e comunidades, com sua oposição ao conceito de acumulação perpétua, com seu regresso a valores de uso, o Bem Viver, uma ideia em construção, livre de preconceitos, abre as portas para a formulação de visões alternativas de vida. (...)

O modelo capitalista também enxerga a riqueza da terra, mas como possibilidade de enriquecimento pessoal, ideológico, de exploração ilimitada e destruição da biodiversidade. É a inversão total da sabedoria que brota do vínculo com a terra. Gera inúmeras situações de pobreza, miséria, extermínio, doenças, desequilíbrios, dívidas, divisões, injustiças de toda ordem. É a ruptura de nossos vínculos nobres, primários, fontais. É, assim, a ruptura de nosso cordão umbilical com a mãe Terra sem, contudo, nos oferecer condições de sobreviver sem ela. É um círculo vicioso que só se pode quebrar quando nos damos conta do que estamos colocando no centro e modificando esse eixo.

Sim, acreditamos que sempre podemos retomar os caminhos originários, pois eles possuem a sabedoria fontal e, por isso mesmo, são potentes e revolucionários em sua força primária. Essa força está em cada ser, em cada um de nós, mesmo que já tão dispersos e distraídos por outros valores que nos fizeram crer que seriam bons para todos, ou para alguns.

\footnotetext{
${ }^{8}$ Alberto Acosta, o autor que propõe uma ruptura civilizatória e oferece os caminhos para isso, em 2007 pôs os Direitos da Natureza na Constituição do Equador, um feito inédito no mundo. É economista, foi um dos responsáveis pelo plano de governo da Alianza País, partido encabeçado por Rafael Correa, presidente desde então. Acosta foi também Ministro de Energia e Minas do Equador. Mas se distanciou do governo de Correa justamente na fase de implantação da Constituinte. Cf. ACOSTA, A. O Bem Viver. Uma oportunidade para imaginar outros mundos. São Paulo: Elefante, 2016
} 
Se o cuidado das pessoas e o cuidado dos ecossistemas são inseparáveis, isto torna-se particularmente significativo lá onde "a floresta não é um recurso para explorar, é um ser ou vários seres com os quais se relacionar". A sabedoria dos povos nativos da Amazônia "inspira o cuidado e o respeito pela criação, com clara consciência dos seus limites, proibindo o seu abuso. Abusar da natureza significa abusar dos antepassados, dos irmãos e irmãs, da criação e do Criador, hipotecando o futuro". Os indígenas, "quando permanecem nos seus territórios, são quem melhor os cuidam" desde que não se deixem enredar pelos cantos das sereias e pelas ofertas interesseiras de grupos de poder. Os danos à natureza preocupam-nos, de maneira muito direta e palpável, porque - dizem eles - "somos água, ar, terra e vida do meio ambiente criado por Deus. Por conseguinte, pedimos que cessem os maus-tratos e o extermínio da "Mãe Terra". A terra tem sangue e está sangrando, as multinacionais cortaram as veias da nossa "Mãe Terra"'. (QA 42)

Esse é o Bem Viver, uma concepção de vida, de comunhão. Vem dos povos indígenas andinos, nos Aimara (Bolívia), nos Quechua (Bolívia e Equador), e também nos povos Guarani (Brasil, Paraguai): Suma Qamaña em aimara, Sumak Kawsay em quechua, Teko Porã em guarani. Há expressões equivalentes entre os Maya na América Central, em índios da Amazônia e em outros grupos indígenas.

Seguimos na escuta da exortação de nosso Pastor nos aproximando da cosmovisão própria dos povos indígenas.

(...) sem diminuir a importância da liberdade pessoal, ressalta-se que os povos nativos da Amazônia possuem um forte sentido comunitário. Vivem assim "o trabalho, o descanso, os relacionamentos humanos, os ritos e as celebrações. Tudo é compartilhado, os espaços particulares - típicos da modernidade - são mínimos. A vida é um caminho comunitário onde as tarefas e as responsabilidades se dividem e compartilham em função do bem comum. Não há espaço para a ideia de indivíduo separado da comunidade ou de seu território". Estas relações humanas estão impregnadas pela natureza circundante, porque a sentem e percebem como uma realidade que integra a sua sociedade e cultura, como um prolongamento do seu corpo pessoal, familiar e de grupo. (QA 20)

Esta cosmovisão indígena pode nos ajudar a mudar o paradigma antropocêntrico que tem regido as últimas décadas, para um paradigma biocêntrico, ou ainda melhor, um paradigma cosmocêntrico. É a transformação processual, dialogal, com escuta 
atenta às culturas com suas diferentes cosmovisões. Podemos criar espaços de proximidade, de conhecimento, de trocas, de aprendizagem, de compartilhamento concreto, de forma a não nos limitarmos a uma aprendizagem intelectual, mas a nos envolvermos e vivenciarmos juntos outras possibilidades de gerir a vida.

O Papa Francisco compreende que há necessidade de proximidade, de diálogo, de conhecimento e reconhecimento mútuo, a fim de que possamos, juntos, buscar novos caminhos de humanização e cuidado com a Terra.

Quero lembrar agora que "a visão consumista do ser humano, incentivada pelos mecanismos da economia globalizada atual, tende a homogeneizar as culturas e a debilitar a imensa variedade cultural, que é um tesouro da humanidade". Isto afeta muito os jovens, quando se tende a "dissolver as diferenças próprias do seu lugar de origem, transformá-los em sujeitos manipuláveis feitos em série". Para evitar esta dinâmica de empobrecimento humano, é preciso amar as raízes e cuidar delas, porque são "um ponto de enraizamento que nos permite crescer e responder aos novos desafios". Conhecê-las é uma fonte de alegria e sobretudo de esperança que inspira ações válidas e corajosas.(QA 33)

Se confrontarmos as recentes investigações científicas com a milenária cosmovisão indígena, constataremos que são iguais na concepção cósmica sobre a origem da vida e sua harmonização, o que determina sua diferença é a linguagem própria que expressam sua sabedoria. Os teóricos do pensamento complexo e transdisciplinar são alguns que nos indicam esse caminho: Werner Heisengerg, Ilya Prigogine, Paulo Freire, Edgar Morin, Humberto Maturana, Fritjof Capra, Boaventura de Sousa Santos, Basarab Nicolescu, Deepak Chopra, Francisco Varela ${ }^{9}$, entre outros, direcionaram suas reflexões para a complexidade, para a compreensão das redes de cooperação e amorosidade da teia da vida, bem como os questionamentos aos pressupostos da Ciência clássica.

O Bem Viver chama a atenção, portanto, para o lugar onde estamos e para onde desejamos ir. A questão não é imaginária, fantasiosa, ao contrário, é compreender os fundamentos e perceber

\footnotetext{
${ }^{9}$ Werner Heisengerg (1901-1976); Ilya Prigogine (1917-2003); Paulo Freire (19211997); Edgar Morin (1921); Humberto Maturana (1928); Fritjof Capra (1939) Boaventura de Sousa Santos (1940); Basarab Nicolescu (1942); Deepak Chopra (1946); Francisco Varela (1946)
} 
onde estamos traindo esses fundamentos e por onde podemos caminhar para rever estruturas, práticas, filosofias, inspirações, propostas sociais, políticas, econômicas, ambientais, espirituais.

Um questionamento fundamental ao nosso modo de viver é nos darmos conta de que o sistema capitalista é incapaz de produzir o bem viver de todos os cidadãos. Para sustentar o modelo capitalista os governos priorizam mega investimentos, grandes barragens, exploração mineral, monoculturas que degradam o ambiente e envenenam a terra, as águas e todos os seres vivos. Consumismo e fome são expressões desse desequilíbrio na distribuição dos bens da terra. Capital e produção representam relações sociais mediadas por exploração, alienação e coisificação. A relação utilitarista custo-benefício não é uma mera relação comercial com sua lógica própria. Nela está embutida uma relação social. ${ }^{10}$ Mais uma vez, o Papa Francisco nos auxilia nessa reflexão e convoca a uma mudança em nossa forma de cuidar da Terra e uns dos outros.

Esta história de sofrimento e desprezo não se cura facilmente. E a colonização não para; embora em muitos lugares se transforme, disfarce e dissimule, todavia não perde a sua prepotência contra a vida dos pobres e a fragilidade do meio ambiente. (QA 16)

É um modelo que apresenta duas grandes falhas: conceber que os recursos da terra são inesgotáveis e permitir que uma pequena porção da humanidade acumule as riquezas produzidas com o trabalho, o sofrimento e a morte de milhões de outros seres humanos. $^{11}$

Diante desse sistema que gera tamanhas injustiças e desigualdades, os princípios do Bem Viver nos fazem repensar todo esse modelo e modificar nossas relações, cultivando relações de reciprocidade, respeito e valorização de todas as formas de vida.

Nesse dinamismo em que a vida nos convoca a sermos mais comunhão e menos ruptura, pouco a pouco, está penetrando uma

\footnotetext{
${ }^{10}$ Cf. SUESS, P. Elementos para a busca do bem viver - sumak kawsay - para todos e sempre. In: CIMI, 2010. Disponível em https://cimi.org.br/2010/12/elementospara-a-busca-do-bem-viver-sumak-kawsay-para-todos-e-sempre. Acesso em fevereiro de 2020.

${ }^{11}$ Cf. BONIN, I. O Bem Viver indígena e o futuro da humanidade. In: CIMI, 2015. Disponível em https://cimi.org.br/o-bem-viver-indigena-e-o-futuro-da-humanidade. Acesso em fevereiro de 2020.
} 
nova visão na consciência latinoamericana e, ao vislumbrá-la e aceitá-la, nos permitimos reinventar o sentido da vida a partir deste novo olhar. Daqui nos chega a esperança e também uma ética de responsabilidade comunitária, com o presente e o futuro. Uma ética que reverencia a sabedoria ancestral e fontal e, nessa fonte pura, se deixa nutrir por essa água que tudo pode renovar e retroalimentar.

Estamos convocados a nos compreendermos, mais uma vez, como filhos e filhas da Terra. É uma relação filial, amorosa que necessita ser resgatada para que daí nasça um novo ser, com novas escolhas radicais, fundamentais e transformadoras. Não se trata, portanto, de uma realização imediata de uma ruptura, mas da retomada de um horizonte que recupera a aliança pela preservação da vida no nosso chão comum.

Concluímos com uma composição de Milton Nascimento, que pode nos conduzir para a roda de sabedoria dos povos indígenas, dos povos originários e, de mãos dadas, todos juntos, pisando nosso chão comum, possamos abraçar nossa Mãe Terra e comungarmos amorosamente para que a Vida seja Vida para todos.

De magia, de dança e pés De criança, cantor e mãos Alameda de gente vida Fecha e mata qualquer ferida De carinho, de roda e mãos De esperança, de corpo e pés A paixão que me está surgindo Te tocando, me consumindo A pulsação do mundo é O coração da gente O coração do mundo é A pulsação da gente Ninguém nos pode impor, meu irmão O que é melhor pra gente

\section{Referências Bibliográficas:}

ACOSTA, A. O Bem Viver. Uma oportunidade para imaginar outros mundos. São Paulo: Elefante, 2016

BONIN, I. O Bem Viver indígena e o futuro da humanidade. In: CIMI, 2015. Disponível em https://cimi.org.br/o-bem-viver-indigena-e-ofuturo-da-humanidade. Acesso em fevereiro de 2020. 
COMISSÃO DOMINICANA DE JUSTIÇA E PAZ DO BRASIL. Bem Viver - Bem Conviver: Sumak Kawsay. Agenda Latino Americana Mundial, Goiânia: 2012

FRANCISCO. Carta Encíclica Laudato Si. Sobre o cuidado da casa comum. Vaticano: Libreria Editrice Vaticana, 2015. Disponível em: http://w2.vatican.va. Acesso em fevereiro, 2020

FRANCISCO. Exortação Apostólica Pós-Sinodal Querida Amazonia. Vaticano: Libreria Editrice Vaticana, 2020. Disponível em http://www.vatican.va. Acesso em fevereiro de 2020

FRANCISCO. Exortação Apostólica Evangelii Gaudium sobre o anúncio do Evangelho no mundo atual. São Paulo: Paulinas, 2013

SBARDELOTTO, M. Nem melhor, nem bem: viver em plenitude. Entrevista a Esperanza Martinez. In: Sumak Kawsay, Suma Qamana, Teko Pora. O Bem-Viver. IHU online. São Leopoldo: Unisinos, edição 340: agosto de 2010.2 Disponível em http://www.ihuonline.unisinos.br/artigo/3448-esperanza-martinez. Acesso em fevereiro de 2020.

SUESS, P. Elementos para a busca do bem viver - sumak kawsay para todos e sempre. In: CIMI, 2010. Disponível em https://cimi.org.br/2010/12/elementos-para-a-busca-do-bem-viversumak-kawsay-para-todos-e-sempre. Acesso em fevereiro de 2020.

VARIOS AUTORES. Sumak Kawsay, Suma Qamana, Teko Pora. O Bem-Viver. IHU online. São Leopoldo: Unisinos, edição 340: agosto de 2010

\section{Para refletir:}

1. Neste artigo alguns conceitos são fundamentais, procure pesquisálos e repensar o significado a partir das reflexões acima propostas: desenvolvimento, colonialismo, capitalismo, comunidade, antropocentrismo, cosmocentrismo

2. A partir da leitura acima e de suas pesquisas, o que mais the chama a atenção na proposta do Bem Viver?

3. Quais são as possibilidades que você já vislumbra para esta proposta, e quais são os desafios que estão diante de nós? 